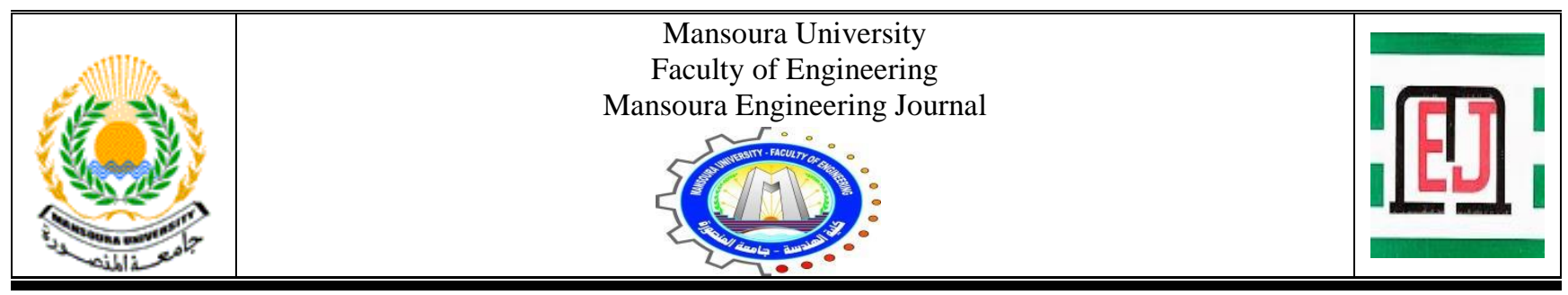

\title{
Performance of Deep Bed Sand Filters in Nom Removal from Water under Different Operational Conditions
}

\author{
Moharram Fouad, Kamal Radwan and Eman Sarhan*
}

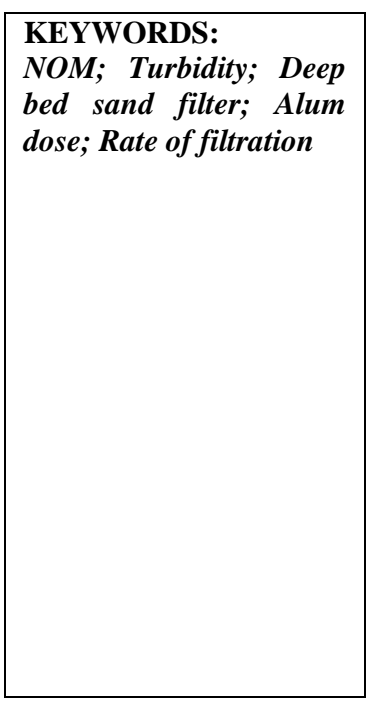

\begin{abstract}
One of the most harmful water contaminants is the natural organic matter (NOM) which is a heterogeneous mixture of naturally occurring organic compounds. That NOM causes aesthetic problems such as color, taste and odor. Accordingly, the existence of NOM in water sets challenges to the drinking water industry and water treatment facilities in terms of operational optimization and proper process design and control. The current research aims to experimentally investigate the performance of deep bed sand filters in removing NOM accompanied with turbidity from water under different operational conditions, particularly, rate of filtration, alum dose and NOM concentration level. The results demonstrated that the removal of high concentrations of NOM in water is recommended to be achieved via using rates of filtration up to moderate values while lower concentrations of NOM are recommended to be removed through slow rates of filtration only. the currentemployed deep bed sand filter is found to be able to reduce the NOM concentrations in the effluent water to nearly one-third or less. Additionally, the highest alum dose among the proposed ones $(15 \mathrm{mg} / \mathrm{L})$ is suitable to remove most of the NOM in the case of low and high influent NOM concentrations. Yet, an alum dose of only $5 \mathrm{mg} / \mathrm{L}$ is sufficient to remove most of the NOM in the case of moderate influent NOM.
\end{abstract}

\section{INTRODUCTION}

$\mathrm{W}$ ITHOUT doubt, water is of great importance for human beings. Clean drinking water is an essential requirement to life and people's survival. If the water they consume is contaminated, it

Received: (09 September, 2021) - Revised: (05 November, 2021) Accepted: (10 November, 2021)

Moharram Fouad, Head of the Department of Public Works Engineering, Faculty of Engineering, Mansoura University (e-mail: mf12317@gmail.com)

Kamal Radwan, Associate Professor at the Department of Public Works Engineering, Faculty of Engineering, Mansoura University(e-mail: kamalradwan58@gmail.com)

*Corresponding Author: Eman Sarhan, Demonstrator at Faculty of Engineering, Delta University for Science \& Technology (e-mail: eng_emansarhan@yahoo.com) negatively affects them and it may cause them several illnesses or even results in fatality. Natural organic matter (NOM) is considered as one of those problematic contaminants that may affect water quality. Additionally, it causes several aesthetic problems such as color, taste and odor.

In general, NOM can be defined as a complex mix of disparate organic materials, e.g., bacteria, viruses, humic and fulvic acids, polysaccharides and proteins [1]. Additionally, NOM mainly consists of compositions having different properties and molecular sizes ranging from small molecules to macromolecules and extensive particles [2]. The mixture of organic compositions of NOM can be divided into two categories, typically hydrophilic and hydrophobic fractions. The first one, hydrophilic fractions of NOM, are formed mainly of aliphatic carbon as well as nitrogenous compounds (e.g., carboxylic acids, carbohydrates and proteins). The 
second category, hydrophobic NOM is mainly composed of humic and fulvic substances in addition to the face that it is rich in aromatic carbon, phenolic structures and conjugated double bonds [3].

NOM primarily consists of humic substances (HSs). It is worth pointing out that HSs generally represent over half of dissolved organic matter [4], [5]. Those, HSs are a set of high molecular weight, yellow to black substances assembled by secondary synthesized reaction [6]. They can be generally identified as being rich in oxygen-containing functional groups such as carboxylic, carbonyl, methoxyl and hydroxyland phenolic function groups [7]. Recently, the classification method of HSs which accepted broadly and used extensively nowadays divides it into three categories, basically humic acid (HA), fulvic acid, and humins. [8].

Shedding light on the HA, the major fraction (40 to 90\%) of the dissolved organic matter in nearly all water supplies [9], it composes of a mix of weak aliphatic (carbon chains) and aromatic (carbon rings) organic acids which are not soluble in water during acidic conditions whereas they are soluble in water during alkaline conditions. HA accounts for that fraction of humus substances that are accelerated from aqueous solution when the $\mathrm{pH}$ is lower than 2 [10].

Moreover, NOM influences obviously many aspects of water treatment, including the behavior of the unit processes, application of water treatment chemicals and biological stability of water. Accordingly, NOM acts upon water quality by causing annoying color, taste and odor problems, and as a courier of metals and hydrophobic organic chemicals. Additionally, NOM is responsible for most of the coagulant and disinfectant use in water treatment. It has a trend to interfere with removal of other pollutants, it takes a part in causing corrosion and it performs as a substrate for bacterial growth in the distribution system [11]. Also, NOM has been remarked as the major contributor to the disinfection byproduct (DBP) formation.

Numerous water treatment methods were utilized in literature to remove NOM from drinking water with different degrees of success, e.g., coagulation, membrane filtration, etc. Coagulation is defined as a water treatment process in which the repulsive potential of electrical double layers of colloids decreases in such a manner that micro-particles can be composed. These prementioned micro-particles crash into each other and produce larger particles (flocs) during the flocculation process. Next, the floc either floats to the top or falls to the bottom of the liquid and can be simply filtered then. The main objective of coagulation process is to form particles of size that can be removed via settlement, flotation or filtration [12]. Several previous studies in literature illustrated that the employment of coagulation in water treatment successfully limited turbidity and color. However, optimum conditions for turbidity or color removal are not always the same as those for NOM removal [13-15].

Various factors affect the efficiency of the coagulation process in the removal of NOM, like coagulant type and dosage, mixing conditions, $\mathrm{pH}$, temperature, particle and NOM properties [16-21].
Usually, aluminum sulphate $\left(\mathrm{Al}_{2}\left(\mathrm{SO}_{4}\right)_{3}\right)$, alum, is the most used coagulant. Yet, the use of alum can cause, especially in the case of cold temperatures or at low $\mathrm{pH}$ levels, relatively high aluminum residuals in the effluent water, which results in serious health risks or variety of problems in distribution system [22], [23]. However, this can be avoided by pH control [24], [25]. Additionally, it is also detected that increasing the alum dose enhances NOM removal to a certain limit although NOM removal is not significantly changed at very high doses $(>100 \mathrm{mg} / \mathrm{L})$.

$\mathrm{PH}$ of the water during NOM removal process has a significant effect on coagulation efficiency. Optimum $\mathrm{pH}$ for the alum coagulation was found to be in the range of 5.0-6.5 (with alum doses between 5 and $100 \mathrm{mg} / \mathrm{L}$ ) [21, 26-32].

Next, the subsequent stage of NOM removal which should come after coagulation process is the deep bed filtration. The deep bed filtration mechanism is based on the fact that the flocs previously formed in coagulation process should pass through a granular medium, typically sand with a depth ranging from $0.5 \mathrm{~m}$ to $2.0 \mathrm{~m}$. The suspended particles are then retained within the depth of the filter media. In the beginning of the filtration head loss is very small, but as the bed gets clogged, the head loss increases till the rate of filtration becomes very low and the filter bed requires to be washed [33].

Many studies dealt with the deep bed filter and its performance in the removal of turbidity from water [34],[35]. However, no sufficient studies investigated these deep bed sand filters in the removal of NOM accompanied with turbidity from water. Accordingly, the main objective of the current research is to evaluate the performance of deep bed sand filters in removing NOM accompanied with turbidity from water and to determine the validity of that technique. Also, the effect of alum dose on the effluent water quality is going to be investigated in order to obtain the optimum dose required to remove the most affordable quantity of NOM.

\section{Materials AND MethodS}

A long experimental testing program is adopted as the backbone of the work in the current research. The program is intended to cover the main operation conditions for the deep bed sand filter. That program includes a number of 36 runs. These runs may be basically described as (3 filtration rates $\times 4$ alum doses $\times 3$ NOM concentrations accompanied with water turbidity).

For the sake of the experimental testing, a pilot plant (Fig. 1) is manufactured and constructed in the Laboratory of Sanitary Engineering, Faculty of Engineering, Mansoura University. This pilot plant provides the ability to monitor the media and water levels, during the different operations modes, though glass side located in its top segment.

The experimental setup consists of six primary parts as follows. (a) Feeding tanks in which the synthetic water with NOM and turbidity is prepared, (b) 0.45 HP feeding pump by which the synthetic water passes from feeding tanks to a 
constant head tank, (c) constant head tank to which the synthetic water is fed before entering the filtration column in order to ensure a constant discharge to the filtration column regardless of the difference in water levels before and after it, (d) galvanized steel filtration column which is the major segment of the pilot plant with a total height 2.5 meters divided into two segments each of $1.25 \mathrm{~m}$ height and it has a square cross section of $15 \times 15 \mathrm{~cm}$ while one side of the upper segment of the filtration column is made of glass to allow monitoring water inside, (e) two $0.45 \mathrm{HP}$ backwash pumps are installed for backwashing purpose, and finally, (f) fittings and Plastic connecting pipes with different shapes and diameters are used in different locations in the pilot plant.
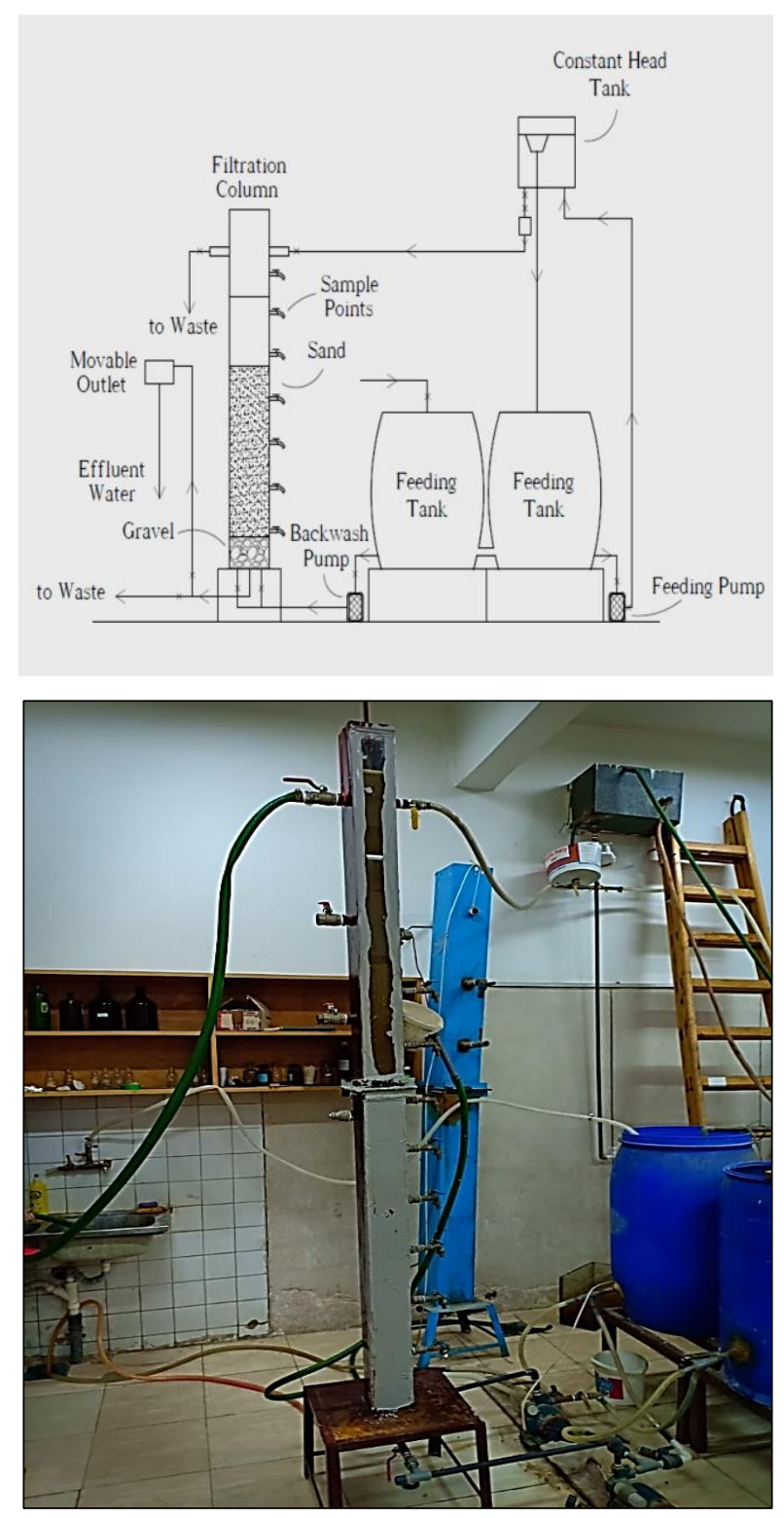

Fig. 1 Pilot plant used in experimental testing

In the current research, the filtration column is filled with uniform sand of a total depth of $1.2 \mathrm{~m}$ resting on a gravel layer of $0.2 \mathrm{~m}$ depth. The utilized sand has a size of 0.7-1.0 mm, porosity of 0.38 , and dry density of $1.65 \mathrm{gm} / \mathrm{cm}^{3}$ while its specific gravity is 2.55 . Moreover, uniformity coefficient $C_{u}$ of the sand media is equal to 1.1. The gravel layer beneath the sand has a size of 2.0-9.0 mm. Existence of the gravel layer is crucial to prevent media particles from clogging the underdrain orifice.

The water to be investigated in this thesis comprises two different contaminants. Definitely, NOM and turbidity. Since it is not trivial task to transport natural water from water sources to the laboratory in Mansoura University, synthetic raw water is prepared instead. As mentioned before in the introductory section, HA represents the major fraction of the NOM in water sources. Therefore, contamination of water with NOM is simulated via adding HA to tape water collected in the feeding tanks. The utilized HA is manufactured by Black Gold. That particular HA consists of $80 \%$ HSs, $10 \%$ Potassium, in addition to $10 \%$ of some minor elements. Since HA is insoluble in water in normal conditions, it is first necessary to dissolve it in a basic solution such as $\mathrm{NaOH}$ and bring down the $\mathrm{pH}$ to the required level by slowly adding acid solution [6]. The synthetic water is prepared in different levels of NOM as required. The water in the feeding tanks, precontaminated with NOM, is then mixed with fine clay. Obviously, different quantities of clay can be used to produce the required turbidity levels. The suspension is the stirred regularly for about 10 minutes to achieve a uniform dispersion of clay particles into water. Finally, water is allowed to settle for at least 20 minutes.

Various filtration parameters are varied in the current research to assess the performance of the deep bed sand filter. The influent water includes different concentrations of NOM $C$ starting from $5 \mathrm{mg} / \mathrm{L}$ TOC and up to $15 \mathrm{mg} / \mathrm{L} \mathrm{TOC}$ with corresponding turbidities $W T$ of 10 to 20 NTU. Filtration rate $V$, which represents one of the main parameters in filtration process, varies from 5 to $15 \mathrm{~m} / \mathrm{hr}$. Since chemical addition plays important role in treatment process and it is also considered as one of the major parameters in this study, alum is added as a coagulant in doses $S$ ranging from 2 to $15 \mathrm{mg} / \mathrm{L}$. Table 1 summarizes different parameters used in the present research.

TABLE 1

VALUES OF THE DIFFERENT PARAMETERS ADOPTED IN THE CURRENT STUDY

\begin{tabular}{l||l||l||l} 
Water $\mathbf{p H}$ & $\boldsymbol{V}(\mathbf{m} / \mathbf{h r})$. & $\boldsymbol{S}(\mathbf{m g} / \mathbf{L})$ & $\begin{array}{l}\boldsymbol{C}(\mathbf{m g} / \mathbf{L} \quad \text { TOC) } \\
\text { and } \boldsymbol{W T} \text { (NTU) }\end{array}$ \\
\hline $5,6,7$ & $5,10,15$ & $\begin{array}{l}\mathrm{S} 1=2, \quad \mathrm{~S} 2=5, \\
\mathrm{~S} 3=10, \mathrm{~S} 415\end{array}$ & $\begin{array}{l}5 \text { and } 10,10 \text { and } \\
15,15 \text { and } 20\end{array}$ \\
& &
\end{tabular}

When the filter run initially begins and water starts to flow into the filter column, a certain period called the ripening period takes place. The ripening period can be defined as the time required for the filter to limit the turbidity of effluent water to a permissible turbidity limit, usually assumed to be 1 NTU. Right after the ripening period ends, the filter enters the working mode which lasts for three hours, in the current study, after the ripening period. Therefore, the total run length is about three to four hours depending on the values of the parameters. 


\section{RESULTS AND DISCUSSION}

A comparative study involving the results of 36 filter runs is conducted in order to evaluate the effect of different parameters on the performance of the deep bed sand filter in removing NOM accompanied with turbidity.

Regarding NOM removal through the filter run, the effluent NOM should be evaluated. Effluent NOM is determined hourly for 3 hours after the ripening period by taking samples of the effluent water from the filter outlet located at its bottom. These filtered water samples are transferred to TOC vials which are then inserted into a TOC analyzer. The TOC analyzer draws the water sample through a needle and oxidizes organic carbon into carbon dioxide. Once the test is completed, the TOC analyzer reports the concentration of TOC.

Increasing the rate of filtration $V$ is found to have a negative effect on the effluent NOM as shown for some filter runs in Fig. 2 since the remaining effluent NOM increases with the increase of the rate of filtration. As the rate of filtration increases, the amount of effluent NOM also increases. This is attributed to the fact that water passing through the filter with high velocity do not have sufficient times for the NOM within it to stuck to filter media. Accordingly, in order to obtain reasonable effluent NOM, high rates of filtration (e.g., $V=15 \mathrm{~m} / \mathrm{hr}$.) are not recommended as the filter performs poorly during some runs corresponding to that particular rate of filtration, as shown in Fig. 2(a). It can be also detected that the two slower filtration rates (i.e., $V=5$ and $10 \mathrm{~m} / \mathrm{hr}$.) have approximately the same effect on the quantity of remaining NOM after filtration process at higher NOM concentrations, i.e., $C=15 \mathrm{mg} / \mathrm{L}$ TOC. On the other hand, at lower NOM concentrations, the effect of the slowest filtration rate $(V=5 \mathrm{~m} / \mathrm{hr}$.) on NOM removal deviates a little from that of the moderate filtration rate $(V=10 \mathrm{~m} / \mathrm{hr}$.) with the first filtration rate having advantage over the second in terms of filter performance. Yet, at lower NOM concentrations, the capability to remove NOM at moderate filtration rate $(V=10 \mathrm{~m} / \mathrm{hr}$. ) is somehow similar to that at the fastest one $(V=15 \mathrm{~m} / \mathrm{hr}$.). Meanwhile, at moderate NOM concentrations $(C=10 \mathrm{mg} / \mathrm{L}$ TOC), there is an apparent difference in the quantity of remaining NOM after filtration process at each filtration rate. Thus, the removal of high concentrations of NOM in water is recommended to be achieved via using rate of filtrations up to moderate values (e.g., from $V=5$ to $10 \mathrm{~m} / \mathrm{hr}$.) while lower concentrations of NOM are recommended to be removed through slow rate of filtrations only ( $V=5 \mathrm{~m} / \mathrm{hr}$.). It is worth pointing out that the effluent NOM is mainly dependent on the rate of filtration.

Rate of filtration is not the only parameter affecting the NOM removal process, but also the alum dose $S$ plays a major role in defining the amount of removed NOM through the filter. Average remaining NOM for each filtration rate is carried out and plotted for each influent NOM value in Fig. 3.
The influent NOM value is also represented in the figure with the horizontal red line. First of all, the capability to remove NOM from water by using direct filtration besides alum is obvious since the filter is able to reduce the NOM concentrations in the effluent water to nearly one-third or less. It is noticeable that the remaining NOM can be represented by a declining curve for various alum doses. The highest alum dose among the proposed ones $(S 1=15 \mathrm{mg} / \mathrm{L})$ is suitable to remove the most NOM in the case of low and high influent NOM concentrations ( $S=5$ and $15 \mathrm{mg} / \mathrm{L}$ TOC). However, an alum dose of only $5 \mathrm{mg} / \mathrm{L}$ is sufficient to remove the most NOM in the case of moderate influent NOM $(C=10 \mathrm{mg} / \mathrm{L}$ TOC) and it has managed to remove additional $3 \%$ of the NOM compared to the case of using $15 \mathrm{mg} / \mathrm{L}$ of alum. Light should be also shed on the effect of alum quantity on the health of the consumers. Utilizing higher alum doses can lead to more residuals in the finishing water; thus, resulting in possible health hazards according to Berbue and Dorea [39]. Anyway, most of the adopted alum doses herein are within the range specified by ECP 201-2010 [40]. In the current test, alum doses of $2,5,10$ and $15 \mathrm{mg} / \mathrm{L}$ have managed to remove an average of 48,63, 66 and $70 \%$ of the influent NOM. These results are noticeably higher than those obtained by Chow et al. [41]. Chow et al. [41] studied the removal of NOM using different alum does by means of membrane filtration. Therefore, the deep bed sand filter, employed in this study, surpass membrane filters and can efficiently remove considerable amount of NOM from water.

The overall filter performance is determined for the current filter runs by the filter performance index, denoted as $P_{i}$. Although that index is commonly used to evaluate the filter performance in removing turbidity from water, a minor modification can be applied to it in order to take into account the amount of influent and effluent NOM. Moreover, the filter performance index takes into account the quality of the filtration process (not the quality of water itself). The mathematical formula to determine the filter performance index is shown below in Equation 1.

$$
P_{i}=\frac{C-R_{n}}{C} \times G
$$

where $C$ and $R_{n}$ represents influent NOM and the amount of remaining NOM at the end of filter run, respectively, while $G$ stands for gallons filtered between two successive backwashes. A filter with high $P_{i}$ can remove considerable amount of NOM while, at the same time, it can be used to filter greater amount of water before getting clogged. The quantity of removed NOM, the amount of the water filtered during the run and the effluent quality are the primary factors influencing the filter performance index. The higher that index, the better the filter performs. Fig. 4 shows the values of the filter performance index at each filtration rate and for each influent NOM at the optimum alum dose of $15 \mathrm{mg} / \mathrm{L}$. The highest filter performance index is found to be 37058 and it is achieved at an influent NOM of $15 \mathrm{mg} / \mathrm{L}$ TOC accompanied with a filtration rate of $5 \mathrm{~m} / \mathrm{hr}$. 
Moving on to turbidity, Fig. 5 shows the effluent turbidity during the first 45 minutes of the first three filter runs. It is obvious that the effluent turbidity at the beginning of ripening period is low. The reason is the existence of remaining clean backwash water in the underdrainage system of the filter. Moving on, the turbidity starts to increase because of the remaining particles that were displaced from the media during backwash. The peak of the turbidity found in the curve results from the influent water enters the filter and mixes with the backwash remaining water in the upper region of the filter. Finally, the turbidity starts to degrade. Note that all of the filter runs exhibits the same trend. Moreover, all of the provided ripening curves are found to be compatible with those provided in literature; refer to [36], [37].

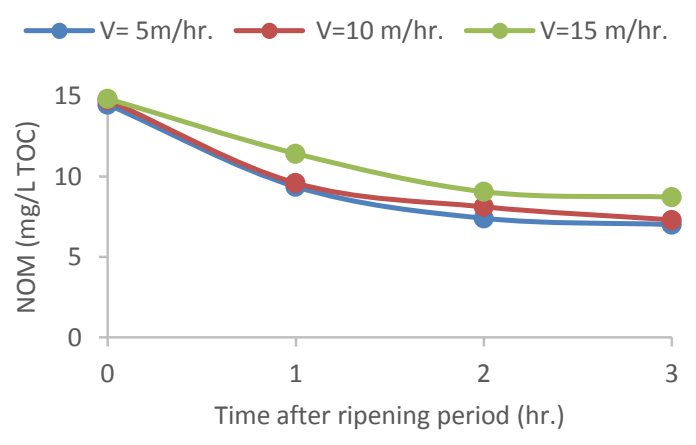

(a)

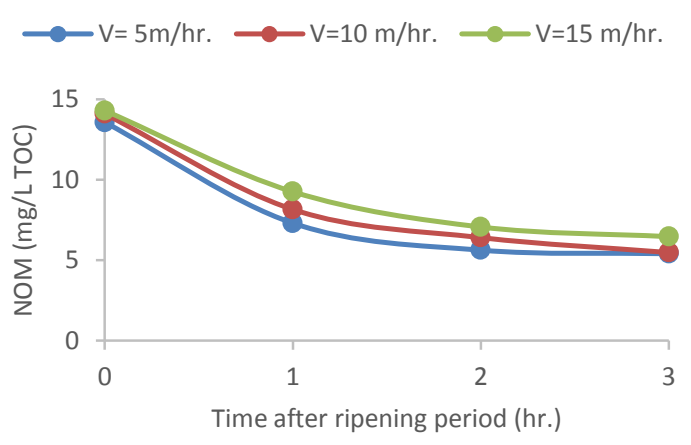

(b)

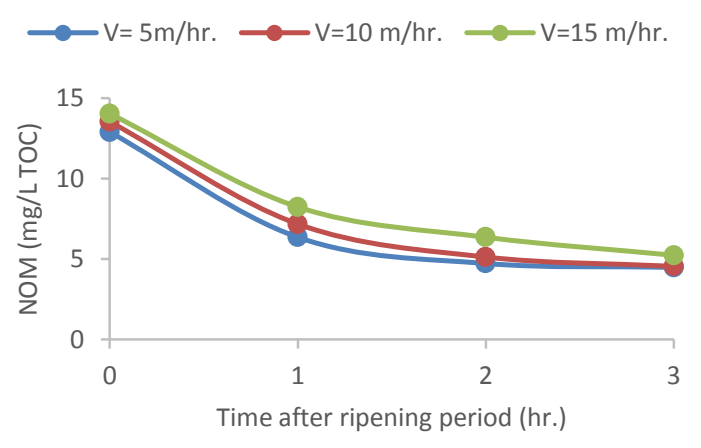

(c)

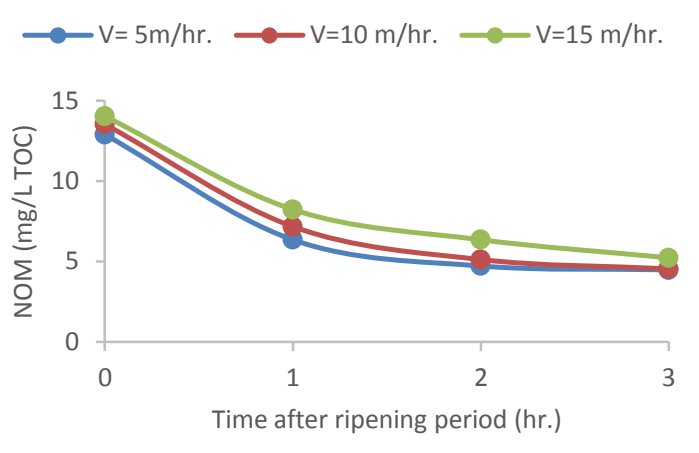

(d)

Fig. 2. Effluent NOM per each hour of the filter run, (a) $\mathrm{C}=15 \mathrm{mg} / \mathrm{L}$ TOC \& S1, (b) C=15 mg/L TOC \& S2, (c) C=15 mg/L TOC \& S3, (d) $\mathrm{C}=15 \mathrm{mg} / \mathrm{L}$ TOC $\& \mathrm{~S} 4$

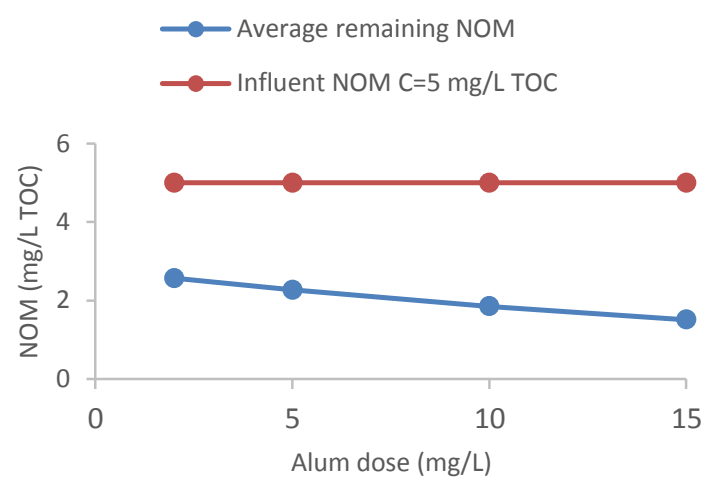

(a)

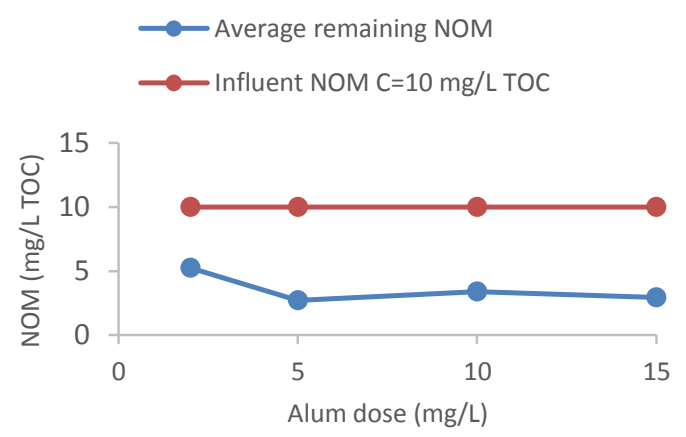

(b)

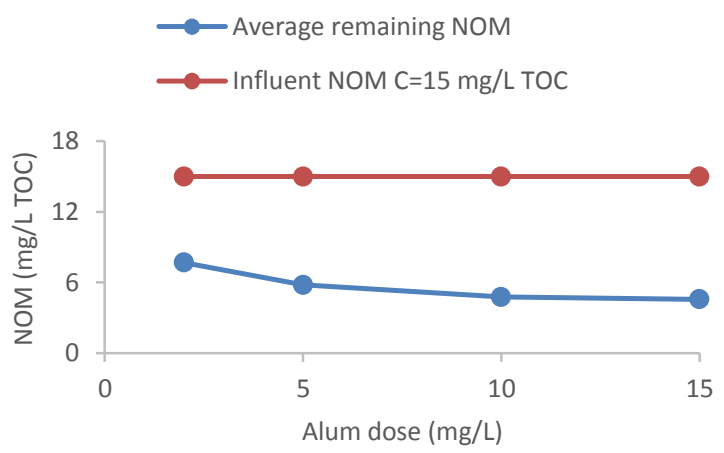

(c)

Fig. 3. Average remaining NOM at the end of the filter run for each alum dose, (a) $\mathrm{C}=5 \mathrm{mg} / \mathrm{L} \mathrm{TOC}$, (b) $\mathrm{C}=10 \mathrm{mg} / \mathrm{L}$ TOC, (c) $\mathrm{C}=15 \mathrm{mg} / \mathrm{L}$ TOC 


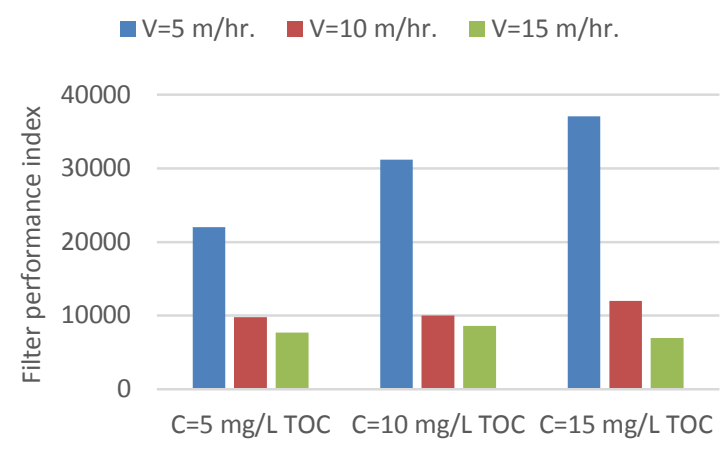

Fig. 4. Filter performance index of the runs with the optimum alum dose of $15 \mathrm{mg} / \mathrm{L}$

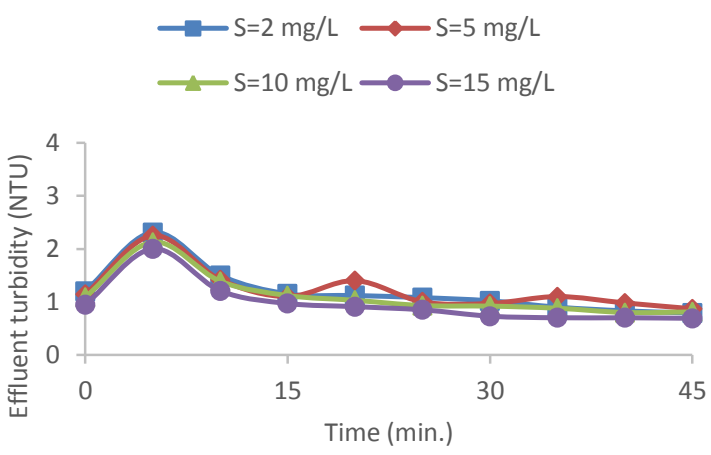

(a)

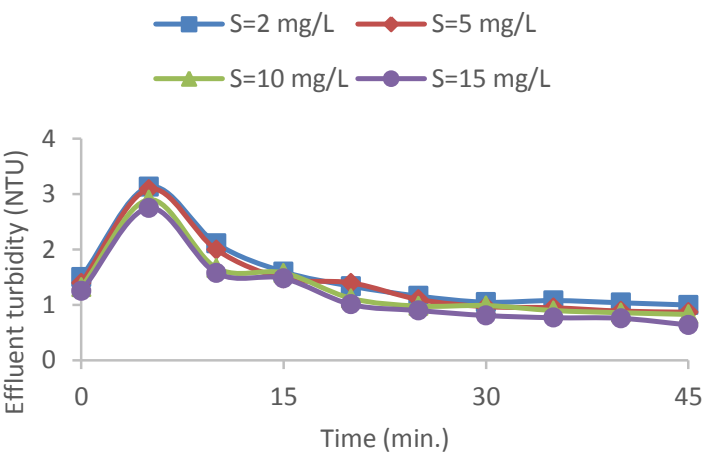

(b)

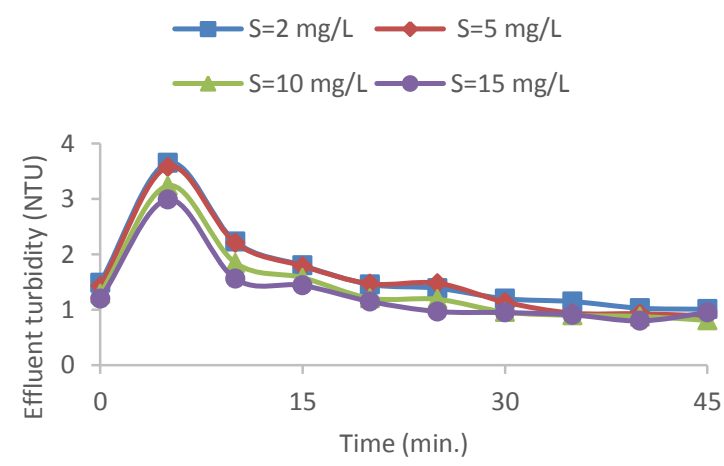

(c)

Fig. 5. Effluent turbidity during the ripening period for an influent turbidity of $10 \mathrm{NTU}$, (a) V=5 m/hr., (b) V=10 m/hr., (c) V=15 m/hr.
Fig. 6 depicts the ripening period in minutes for the 36 filter runs under consideration. It also illustrates that the rate of filtration is directly proportional to the duration of the ripening period in nearly all the runs. For instance, considering only the group of influent turbidity of $10 \mathrm{NTU}$, the average ripening period for the four alum doses at rate of filtration of 5 $\mathrm{m} / \mathrm{hr}$. is found to be 22.5 minute whereas the average ripening periods at rates of filtration of 10 and $15 \mathrm{~m} / \mathrm{hr}$. are 30 and 35.5 minute, respectively. This means that raising the rate of filtration 3 times results in an increase in the ripening period of approximately 58\%. It is also obvious in Fig. 6 that the ripening period is inversely proportional to the alum dose. By increasing alum dose, the ripening time can be reduced. Also, the increased rate of filtration results in an extra duration during the ripening period. Although the difference in the ripening period in the case of using alum doses of 5, 10, and $15 \mathrm{mg} / \mathrm{L}$ is not very large, the difference between them and an alum dose of $2 \mathrm{mg} / \mathrm{L}$ in reducing the ripening period is more significant. Regarding the influent water turbidity, it has significant effect on the length of the ripening period. For instance, fixing the rate of filtration to an average value of 10 $\mathrm{m} / \mathrm{hr}$., Fig. 6 shows that the average required ripening period is 30,49 , and 53 minutes for influent turbidity of 10,15 , and 20 NTU, respectively. So, it can be concluded that limiting influent turbidity can significantly reduce the required ripening time.

It is worth pointing out that the ripening period for some filter runs in the current research ranges from 15 to 72 minute which is extensively beyond the range commonly found in literature [38], [42], [43]. This difference may arise from the fact that Mahanna [42], [43], for instance, only studied water contaminated with turbidity. On the other hand, the adopted synthetic water in the current research is not only contaminated with turbidity but also with NOM which certainly changes the structure of the water and therefore alters its behavior during filtration. Accordingly, a water contaminated with both NOM and turbidity have higher ripening period; consequently, causing loss of higher quantity of water.

In subsequence to the ripening stage, working stage begins in which the suspended particles in the influent water are removed within the sand media depth. Then, the effluent turbidity starts to decrease till reaching the allowable limit. It is worthwhile noting that all of the filter runs lasted for 3 hours after the ripening period, i.e., the full length of the filter run is about 4 hours, more or less. Therefore, the effluent turbidity at the end of each run is observed and normalized through dividing it by the influent turbidity as shown in Fig. 7. Similar to the effluent turbidity during ripening period, the effluent turbidity at the end of each filter run is also dependent on filtration rate and alum dose. Effluent turbidity is found to be directly proportional to the rate of filtration. Higher rates of filtration results in a higher effluent turbidity since water in 
these cases are passing in high velocity through the filter which makes it difficult to get rid of the contaminant particles. In addition, effluent turbidity is inversely proportional to the alum dose because using higher alum doses enhances the filter capability to remove particles. It can be also detected that after 3 hours of filter run subsequent to the ripening period, effluent turbidity is flocculating around the range of 1 NTU which demonstrates that the prementioned duration is sufficient to remove turbidity.

\section{CONCLUSIONS}

An experimental testing program is conducted in the Laboratory of Sanitary engineering, Faculty of Engineering, Mansoura University in order to study the performance of deep bed sand filters in removing natural organic matter (NOM) accompanied with turbidity from water. Performance of the deep bed sand filter is evaluated under different operational conditions like rate of filtration, alum dose and NOM concentration level. Based on the experimental results, the following conclusions are observed:

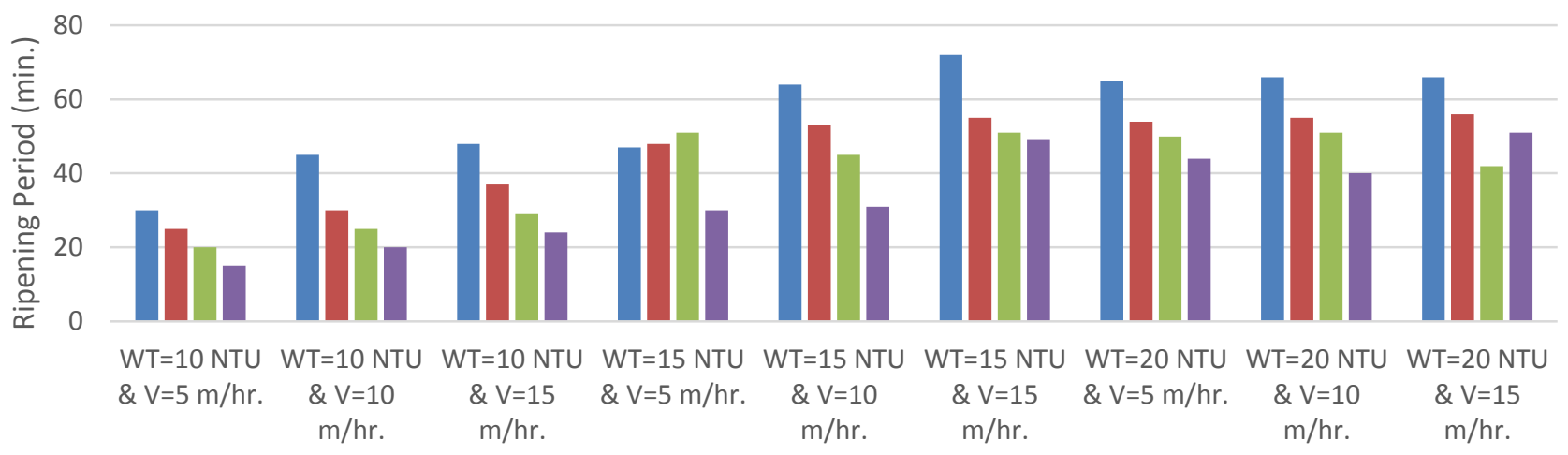

Fig. 6. Duration of the ripening period for each filter run

$\square \mathrm{S} 1 \square \mathrm{S} 2 \mathrm{~S} 3 \mathbf{\mathrm { S }} 4$

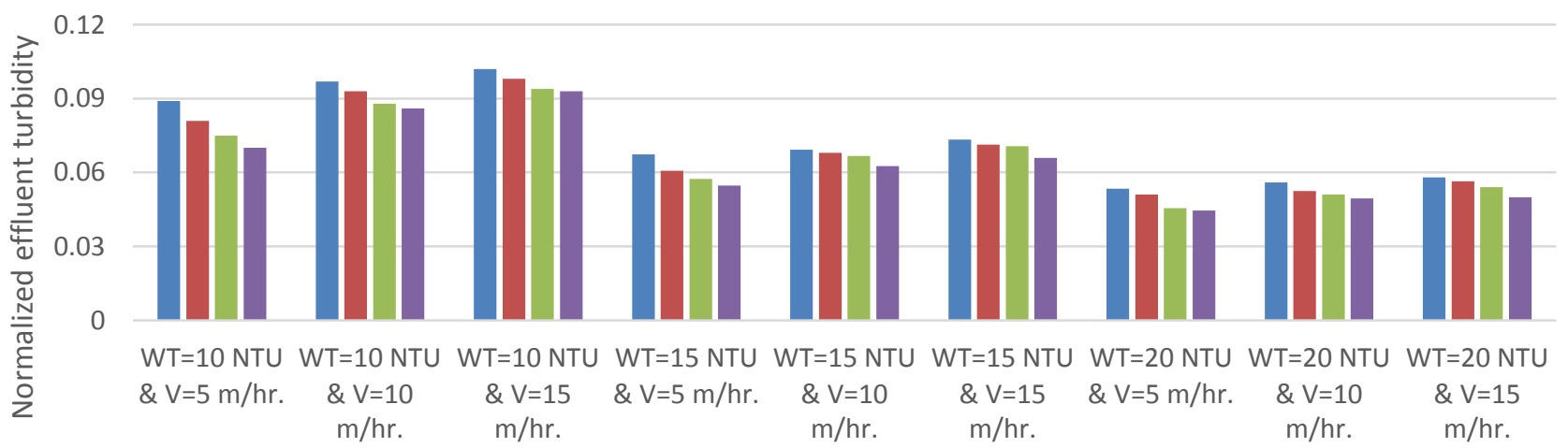

Fig. 7. Duration of the ripening period for each filter run

- removal of high concentrations of NOM in water is recommended to be achieved via using rate of filtrations up to moderate values while lower concentrations of NOM are recommended to be removed the through slow rate of filtrations only.

- With regard to the effect of the alum dose on NOM removal, the current-employed deep bed sand filter is found to be able to reduce the NOM concentrations in the effluent water to nearly one-third or less.
- The highest alum dose among the proposed ones (15 $\mathrm{mg} / \mathrm{L}$ ) is suitable to remove the most NOM in the case of low and high influent NOM concentrations. Yet, an alum dose of only $5 \mathrm{mg} / \mathrm{L}$ is sufficient to remove the most NOM in the case of moderate influent NOM.

- Under certain operational conditions, NOM can be efficiently removed from water through direct filtration (deep bed sand filters). 


\section{AUTHORS CONTRIBUTION}

Moharram Fouad: Substantially contributed the conception or design of the work, data collection and tools, data analysis and interpretation, methodology, project administration, and final approval of the version to be published.

Kamal Radwan: Provided the final approval of the version to be published.

Eman Sarhan: Determined the tools of data collection, data analysis and interpretation, drafting the article, and critical revision of the article.

\section{FUNDING STATEMENT:}

This research did not receive any specific grant from funding agencies in the public, commercial, or not-for-profit sectors.

\section{DECLARATION OF CONFLICTING INTERESTS STATEMENT:}

The author declared that there are no potential conflicts of interest with respect to the research authorship or publication of this article.

\section{REFERENCES}

[1] Vepsäläinen, M., \& Sillanpää, M. (2020). Electrocoagulation in the treatment of industrial waters and wastewaters. In Advanced Water Treatment (pp. 1-78). Elsevier.

[2] Sakarinen, E. (2016). Humic acid removal by chemical coagulation, electrocoagulation and ultrafiltration. M.Sc. thesis, Arcada University for Applied Sciences.

[3] Matilainen, A. (2007). Removal of the natural organic matter in the different stages of the drinking water treatment process, Ph.D. dissertation, Tampere University of Technology.

[4] Metsämuuronen, S., Sillanpää, M., Bhatnagar, A., \& Mänttäri, M. (2014). Natural organic matter removal from drinking water by membrane technology. Separation \& Purification Reviews, 43(1), 1-61.

[5] Anu, M., Mikko, V., \& Mika, S. (2010). Natural organic matter removal by coagulation during drinking water treatment: A review. Advances in Colloid and Interface Science, 159, 189-197.

[6] Stevenson, F. J. (1994). Humus chemistry: genesis, composition, reactions. John Wiley \& Sons.

[7] Wiszniowski, J., Robert, D., Surmacz-Gorska, J., Miksch, K., \& Weber, J. V. (2002). Photocatalytic decomposition of humic acids on TiO2: Part I: Discussion of adsorption and mechanism. Journal of Photochemistry and Photobiology A: Chemistry, 152(1-3), 267-273.

[8] Lee, P. F., Zhang, X., Sun, D. D., Du, J., \& Leckie, J. O. (2008). Synthesis of bimodal porous structured $\mathrm{TiO} 2$ microsphere with high photocatalytic activity for water treatment. Colloids and Surfaces A: Physicochemical and Engineering Aspects, 324(1-3), 202-207.

[9] Kilduff, J. E., Karanfil, T., \& Weber, W. J. (1996). Competitive interactions among components of humic acids in granular activated carbon adsorption systems: effects of solution chemistry. Environmental science \& technology, 30(4), 1344-1351.

[10] Bai, H. (2009). Removal of humic acid in water using an integrated $\mathrm{TiO} 2$ photocatalytic oxidation and membrane system. M.Sc. thesis, Nanyang Technological University.

[11] Sohn, J., Amy, G., Cho, J., Lee, Y., \& Yoon, Y. (2004). Disinfectant decay and disinfection by-products formation model development: chlorination and ozonation by-products. Water Research, 38(10), 24612478.

[12] Binnie, C., Kimber, M., \& Thomas, H. (2017). Basic Water Treatment. ICE Publishing.

[13] Budd, G. C., Hess, A. F., Shorney- Darby, H., Neemann, J. J., Spencer, C. M., Bellamy, J. D., \& Hargette, P. H. (2004). Coagulation applications for new treatment goals. Journal- American Water Works Association, 96(2), 102-113.

[14] Yu, J., Wang, D., Yan, M., Ye, C., Yang, M., \& Ge, X. (2007). Optimized coagulation of high alkalinity, low temperature and particle water: $\mathrm{pH}$ adjustment and polyelectrolytes as coagulant aids. Environmental monitoring and assessment, 131(1), 377-386.

[15] Yan, M., Wang, D., Qu, J., Ni, J., \& Chow, C. W. (2008). Enhanced coagulation for high alkalinity and micro-polluted water: the third way through coagulant optimization. Water research, 42(8-9), 2278-2286.

[16] Sharp, E. L., Jarvis, P., Parsons, S. A., \& Jefferson, B. (2006). Impact of fractional character on the coagulation of NOM. Colloids and Surfaces A: Physicochemical and Engineering Aspects, 286(1-3), 104-111.

[17] Duan, J., \& Gregory, J. (2003). Coagulation by hydrolysing metal salts. Advances in colloid and interface science, 100, 475-502.

[18] Jacangelo, J. G., DeMarco, J., Owen, D. M., \& Randtke, S. J. (1995). Selected processes for removing NOM: an overview. Journal- American Water Works Association, 87(1), 64-77.

[19] Kim, H. C., Lee, S., Byun, S. J., \& Yu, M. J. (2006). Application of improved rapid mixing for enhanced removal of dissolved organic matter and DBPFP (disinfection by-product formation potential) control. Water Science and Technology: Water Supply, 6(1), 49-57.

[20] Sharp, E. L., Jarvis, P., Parsons, S. A., \& Jefferson, B. (2006). The impact of zeta potential on the physical properties of ferric- NOM flocs. Environmental science \& technology, 40(12), 3934-3940.

[21] Qin, J. J., Oo, M. H., Kekre, K. A., Knops, F., \& Miller, P. (2006). Impact of coagulation $\mathrm{pH}$ on enhanced removal of natural organic matter in treatment of reservoir water. Separation and Purification Technology, 49(3), 295-298.

[22] Chow, C. W., van Leeuwen, J. A., Fabris, R., \& Drikas, M. (2009). Optimised coagulation using aluminium sulfate for the removal of dissolved organic carbon. Desalination, 245(1-3), 120-134.

[23] Berube, D., \& Dorea, C. C. (2008). Optimizing alum coagulation for turbidity, organics, and residual Al reductions. Water Science and Technology: Water Supply, 8(5), 505-511.

[24] Matsukawa, S., Itoho, S., Habuthu, S., \& Aizawa, T. (2006). An approach to residual aluminium control at Nisiya purification plant, Water Works Bureau, Yokohama. Water Science and Technology: Water Supply, 6(4), 67-74.

[25] Berube, D., \& Dorea, C. C. (2008). Optimizing alum coagulation for turbidity, organics, and residual Al reductions. Water Science and Technology: Water Supply, 8(5), 505-511.

[26] Smith, E., \& Kamal, Y. (2009). Optimizing treatment for reduction of disinfection by-product (DBP) formation. Water Science and Technology: Water Supply, 9(2), 191-198.

[27] Chow, C. W., van Leeuwen, J. A., Fabris, R., \& Drikas, M. (2009). Optimised coagulation using aluminium sulfate for the removal of dissolved organic carbon. Desalination, 245(1-3), 120-134.

[28] Chong Soh, Y., Roddick, F., \& van Leeuwen, J. (2008). The impact of alum coagulation on the character, biodegradability and disinfection byproduct formation potential of reservoir natural organic matter (NOM) fractions. Water Science and Technology, 58(6), 1173-1179.

[29] Yu, J., Wang, D., Yan, M., Ye, C., Yang, M., \& Ge, X. (2007). Optimized coagulation of high alkalinity, low temperature and particle water: $\mathrm{pH}$ adjustment and polyelectrolytes as coagulant aids. Environmental monitoring and assessment, 131(1), 377-386.

[30] Uyguner, C. S., Bekbolet, M., \& Selcuk, H. (2007). A comparative approach to the application of a physico- chemical and advanced oxidation combined system to natural water samples. Separation Science and Technology, 42(7), 1405-1419.

[31] Uyak, V., \& Toroz, I. (2007). Disinfection by-product precursors reduction by various coagulation techniques in Istanbul water supplies. Journal of hazardous materials, 141(1), 320-328.

[32] Shin, J. Y., Spinette, R. F., \& O'melia, C. R. (2008). Stoichiometry of coagulation revisited. Environmental science \& technology, 42(7), 25822589.

[33] Birdie, G. S., \& Birdie, J. S. (2004). Water Supply \& Sanitary Engineering seventh revised \& enlarged edition. Dhanpat Rai Publishing Company.

[34] Chang, J. S., \& Vigneswaran, S. (1990). Ionic strength in deep bed filtration. Water Research, 24(11), 1425-1430.

[35] Vigneswaran, S., \& Chang, J. S. (1991). Effect of media pore size distribution on deep-bed filtration. Separations Technology, 1(5), 259266. 
[36] Amburgey, J. E. (2005). Optimization of the extended terminal subfluidization wash (ETSW) filter backwashing procedure. Water Research, 39(2-3), 314-330.

[37] Amirtharajah, A., \& Wetstein, D. P. (1980). Initial degradation of effluent quality during filtration. Journal- American Water Works Association, 72(9), 518-524.

[38] Follett, M. (2013). Assessment of Filter Ripening at a Direct Filtration Plant, Halifax, NS.

[39] Berube, D., \& Dorea, C. C. (2008). Optimizing alum coagulation for turbidity, organics, and residual Al reductions. Water Science and Technology: Water Supply, 8(5), 505-511.

[40] Permanent Committee for the Preparation of the Egyptian Code of Practice (2010). Egyptian code of practice for design standards and construction rules for pipelines of drinking water networks and sewage ECP 102-2010. Housing and Building National Research Center, Giza, Egypt.

[41] Chow, C. W., van Leeuwen, J. A., Fabris, R., \& Drikas, M. (2009). Optimised coagulation using aluminium sulfate for the removal of dissolved organic carbon. Desalination, 245(1-3), 120-134.

[42] Mahanna, H., Fouad, M., Radwan, K., \& Elgamal, H. (2015). Predicting of effluent turbidity from deep bed sand filters used in water treatment. In the beginning, 9(10), 11.

[43] Mahanna, H., Radwan, K., Fouad, M., \& Elgamal, H. (2018). Effect of operational conditions on performance of deep sand filter in turbidity removal. Trends Tech. Sci. Res, 2(5), 1-7.

\section{Title Arabic:}

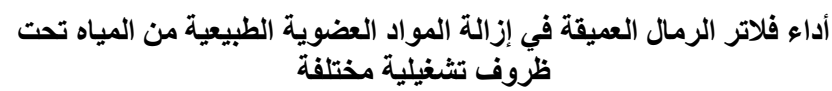

\section{Arabic Abstract:}

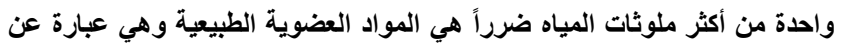

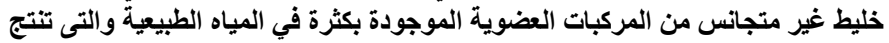

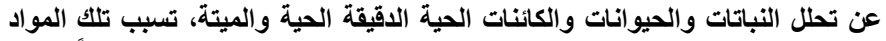

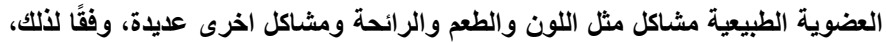

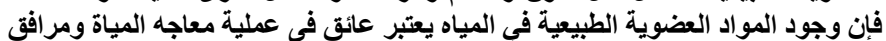

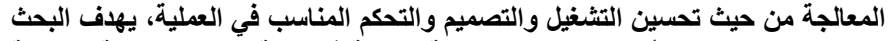

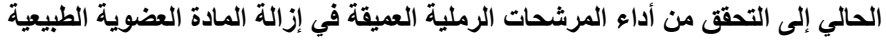

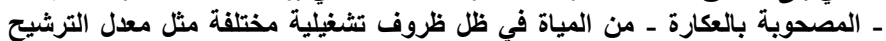

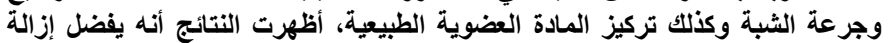

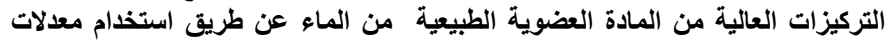

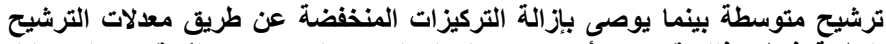

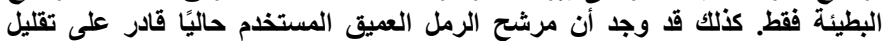

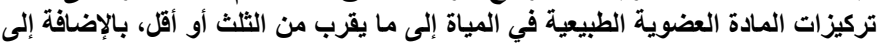

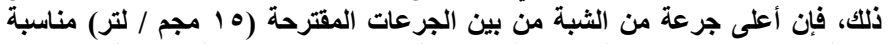

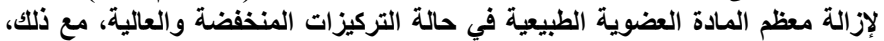

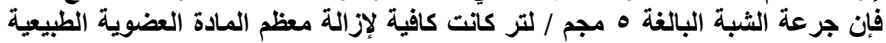

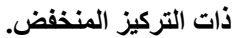

